Syntax Literate: Jurnal Ilmiah Indonesia p-ISSN: 2541-0849

e-ISSN: 2548-1398

Vol. 7, No. 1, Januari 2022

\title{
PERFORMA PRODUKSI SAPI BALI PADA KETINGGIAN TEMPAT YANG BERBEDA DI KABUPATEN NGADA, FLORES, NUSA TENGGARA TIMUR
}

\author{
Ngiso Bhae, Suyadi, M. Nur Ihsan
}

University of Brawijaya, Surabaya, Indonesia

Email: tian.ngiso@gmail.com, suyadi12@gmail.com,nurihsan03@gmail.com

\begin{abstract}
Abstrak
Performans produksi pada sapi dipengaruhi oleh faktor lingkungan berupa iklim, pakan, dan manajemen. Tujuan penelitian ini adalah melakukan kajian performa produksi sapi Bali pada dua ketinggian tempat yang berbeda di Kecamatan Bajawa dan Kecamatan Bajawa Utara untuk dataran tinggi (1000 m dpl) dan Kecamatan Riung Barat dan Golewa Selatan untuk dataran rendah (100 m dpl) di Kabupaten Ngada, Nusa Tenggara Timur. Penelitian survey yang dipilih secara purposive sampling yaitu sampel penelitian digunakan dalam penelitian ini adalah ternak sapi Bali sebanyak 246 ekor yang ada di 4 Kecamatan. Kecamatan Bajawa dan Kecamatan Bajawa Utara yang mewakili dataran tinggi sebanyak 131 ekor serta Kecamatan Riung Barat dan Golewa Selatan yang mewakili dataran rendah sebanyak 115 ekor. Data primer dari penelitian ini berupa bobot lahir, bobot sapih, bobot dewasa, dan pertambahan bobot badan harian (PBBH). Hasil penelitianmenunjukan ketinggian tempat dan lokasi berpengaruh tidak nyata $(\mathrm{P}>0.05)$ terhadap bobot badan pedet, bobot sapih, Bobot Badan umur 2-3 tahun dan

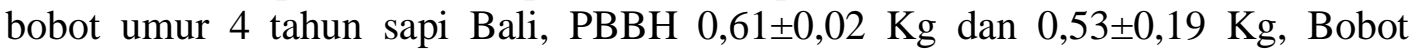

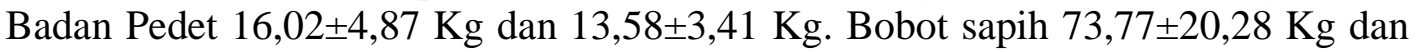
$69,88 \pm 14,51 \mathrm{Kg}$, Bobot Badan Bali $2-3$ tahun 168,57 $\pm 26,29 \mathrm{Kg}$ dan160,97 $\pm 21,01$ Kg,Bobot Badan umur 4 tahun $404 \pm 89,20 \mathrm{Kg}$ dan $366,14 \pm 95,20$. Terdapat perbedaan yang nyata $(\mathrm{P}<0.05)$ untuk umur $3-4$ Tahun $289,74 \pm 35,30 \mathrm{Kg}$ dan $247,25 \pm 20,57 \mathrm{Kg}$.
\end{abstract}

Kata Kunci: peformance; produksi; berat badan; dataran tinggi; dataran rendah

\section{Abstract}

The productive performance of cattle is influenced by environmental factors such as climate, feed, and management. This study aimed to examine the productive performance of Bali cattle at two different altitude areas, namely in Bajawa and North Bajawa districts (1,000 $\mathrm{m}$ above sea level) for high altitude areas and West Riung and South Golewa districts (100 $\mathrm{m}$ above sea level) for low altitude areas of Ngada Regency, East Nusa Tenggara. The method used in this study was the survey method. The materials used in this study were 246 Bali cattle with 131 heads in high altitude areas and 115 heads in low altitude areas. The Bali cattle were chosen by purposive sampling. The variables observed were birth weight, weaning weight, mature weight, and daily weight gain. The results showed that the altitudes did not significantly $(P>0.05)$ affect birth weight, weaning weight, body weight at 2-3 years of age, body weight at 4 years of age, and daily weight gain. The birth

$\begin{array}{ll}\text { How to cite: } & \text { Ngiso Bhae, Suyadi, M. Nur Ihsan (2022) Performa Produksi Sapi Bali Pada Ketinggian Tempat yang } \\ & \text { Berbeda Di Kabupaten Ngada, Flores, Nusa Tenggara Timur. Syntax Literate: Jurnal Ilmiah Indonesia, 7(1). } \\ & \text { http://dx.doi.org/10.36418/ Syntax-Literate.v7i1.4064 } \\ \text { E-ISSN: } & \text { 2548-1398 } \\ \text { Published by: } & \text { Ridwan Institute }\end{array}$


weightwere $16.02 \pm 4.87$ and $13.58 \pm 3.41 \mathrm{~kg}$, the weaning weight were $73.77 \pm 20.28$ and $69.88 \pm 14.51 \mathrm{~kg}$, the body weight at $2-3$ years of age were $168.57 \pm 26.29$ and $160.97 \pm 21.01 \mathrm{~kg}$, the body weight at 4 years of age were $404 \pm 89.20$ and $366.14 \pm 95.20 \mathrm{~kg}$, and the daily weight gain were $0.61 \pm 0.02$ and $0.53 \pm 0.19 \mathrm{~kg}$ for Bali cattle at high and low altitude areas, respectively. There was a significantly different $(P<0.05)$ of body weight of Bali cattle at 3-4 years of age with $289.74 \pm 35.30$ and $247.25 \pm 20.57 \mathrm{~kg}$ for those at high and low altitude areas, respectively.

Keywords: performance; production; body weight; high altitude area; andlow altitude area

Received: 2021-12-20; Accepted: 2022-01-05; Published: 2022-01-15

\section{Pendahuluan}

Potensi produktivitas ternak pada dasarnya dipengaruhi faktor genetik, lingkungan serta interaksi antar genetik dan lingkungan (Karnaen \& Arifin, 2009). Faktor genetik berpengaruh adalah bangsa ternak sedangkan faktor lingkungan antara lain, pakan, iklim, ketinggian tempat, bobot badan, penyakit, kebuntingan, bulan laktasi, dan jarak beranak (Epaphras, Karimuribo, \& Msellem, 2004).

Ketinggian tempat lokasi pemeliharaan ternak dapat mempengaruhi penampilan produksi dan reproduksi sapi Bali, Hasil penelitian (Calderon, A., D.V. Armstrong, D.E. Ray, S.K. Denise, 2005) dan (Umiyasih, Yusran, Wijono, \& Wahyono, 2000) menyatakan bahwa terdapat perbedaan yang nyata terhadap penampilan produksi dan reproduksi ternak di dataran rendah dan dataran tinggi. Perbedaan produktivitas ini berkaitan dengan faktor suhu dan kelembapan udara. Interaksi suhu dan kelembaban udara atau Temperature Humidity Index (THI) dapat mempengaruhi kenyamanan hidup ternak.

Sejalan dengan proses transformasi struktur perekonomian Kabupaten Ngada yang telah dan akan terus berlanjut mengarah pada struktur yang lebih seimbang. Diperkirakan sektor pertanian lebih khususnya peternakan akan terus meningkat sejalan dengan pertumbuhan penduduk di Kabupaten Ngada yang akan datang, karena sektor ini masih merupakan sumber mata pencaharian utama bagi sebagian besar angkatan kerja di Kabupaten Ngada. Agar tercapai apa yang diharapkan, maka sangat perlu para perencana pembangunan peternakan di daerah memperhatikan berbagai lingkungan strategis serta arah dan kebijakan pembangunan jangka panjang. Pembangunan peternakan dalam rangka pembangunan ekonomi daerah pada dasarnya merupakan peningkatan efisiensi usaha dan pemanfaatan serta produktivitas sumber daya pertanian yang sudah dimiliki melalui integrasi dan peningkatan peran swasta serta melibatkan secara aktif petani/peternak dalam kemitraan yang menguntungkan antara pelaku ekonomi, sementara Pemerintah akan lebih berperan sebagai fasilitator dan dinamisator pembangunan.

Dalam upaya peningkatan produktivitas ternak sapi Bali secara maksimal diperlukan data dan informasi yang obyektif, aktual dan memenuhi standar informasi. 
Untuk mengetahui potensi produktivitas sapi Bali di Kabupaten Ngada maka perlu dilakukan evaluasi terhadap sifat-sifat produksi dari sapi-sapi Bali yang berada di Kabupaten Ngada. Pengamatan ini diperlukan untuk mendapatkan data tentang tingkat produksi sapi Bali dan proses pengembangan sapi Bali di Kabupaten Ngada.

\section{Metode Penelitian}

Penelitian inidilakukan di peternakan rakyat di Kabupaten Ngada, Flores, Nusa Tenggara Timur (NTT). Penelitian ini dilaksanakan selama 4 bulan dari bulan November 2017 sampai Februari 2018. Penelitian ini dilakukan dengan metode survey, dimana penelitian dilakukan mengampilan sampel dalam satu populasi dengan menggunakan daftar terstrukur (kuesioner) sebagai alat pengambilan data yang pokok.Sampelpenelitian digunakan dalam penelitian ini adalah ternak sapi Bali sebanyak 246 ekor (Data Produksi) yang ada di 4 Kecamatan. Kecamatan Bajawa dan Kecamatan Bajawa Utara yang mewakili Dataran tinggi 131 ekor serta Kecamatan Riung Barat dan Golewa Selatan yang mewakili Daratan rendah 115 ekor yang ada di Kabupaten Ngada. Data primer dari penelitian ini berupa bobot lahir, bobot sapih, bobot dewasa dan pertambahan bobot badan harian $(\mathrm{PBBH})$ yang ada di Kabupaten Ngada. Survei ini dilakukan pada 23 kelompok ternak aktif dari masyarakat termasuk 7 orang Inseminator dan penyuluh lapangan yang bertanggung jawab di 4 kecamatan tersebut.

Pemilihan lokasi penelitian dilakukan secara sengaja (purposive sampling) yaitu berdasarkan pertimbangan bahwa di daerah tersebut merupakan daerah yang memiliki populasi sapi Bali terbanyak dan memiliki ketinggian $\pm 1000 \mathrm{~m}$ dpl untuk dataran tinggi dan ketinggian $\pm 100 \mathrm{~m}$ dpl untuk dataran rendah. Data primer diperoleh melalui pengamatan langsung pada objek penelitian dan wawancara dengan para peternak maupun petugas IB dan dengan menggunakan kuesioner yang telah dipersiapan sebelumnya. Data sekunder dapat diperoleh dari kecamatan-kecamatan yang di amati dan Dinas peternakan Kabupaten Ngada.

Penentuan besarnya sampel dapat didasarkan pada jumlah subieknya apabila kurang dari 100, lebih baik diambil semua sehinggah merupakan penelitian populasi, selanjutnya jika jumlah subieknya besar dapat di ambil antara 10-15\% atau lebih tergantung dari:

a) Kemampuan peneliti dilihat dari waktu, tenaga dan dana.

b) Luas wilayah pengamatan dari setiap subiek.

c) Besar kecilnya resiko yang ditanggung oleh peneliti.

Selanjutnya sifat-sifat atau ciri-ciri yang dikandung oleh subiek bertalian erat dengan homogenitas subiek dalam populasi (Arikunto, 2010). 


\begin{tabular}{|c|c|c|c|c|}
\hline D & $\begin{array}{r}\text { Tabe } \\
\text { nah pe }\end{array}$ & 1 & & \\
\hline Ketinggitan Tempat & Variab & 1 Produ & & \\
\hline & $\begin{array}{l}\text { Bobot } \\
\text { Lahir }\end{array}$ & $\begin{array}{l}\text { Bobot } \\
\text { Sapih }\end{array}$ & $\begin{array}{l}\text { Bobot } \\
\text { Dewasa }\end{array}$ & РВBН \\
\hline $\begin{array}{l}\text { Dataran Tinggi }( \pm 1000 \mathrm{~m} \\
\mathrm{dpl})\end{array}$ & & & & \\
\hline $\begin{array}{l}\text { Dataran Rendah }( \pm 500 \mathrm{~m} \\
\text { dpl) }\end{array}$ & & & & \\
\hline
\end{tabular}

\section{Peubah Yang Di Amat}

a) Bobot Lahir

Pengukuran bobot lahir dari seekor sapi yang baru lahir sampai umur 3 hari di timbang langsung menggunakan timbangan.

b) Bobot Badan Ternak Sapi Bali

Bobot badan ternak sapi Bali bali yang ada di daerah penelitian di tentukan melalui pengukuran Lingkar dada, panjang badan dan tinggi pundak.

a. Pengukuran Panjang Badan dan Lingkar Dada

$\checkmark$ Panjang badan (PB), jarak antara ujung samping tulang bahu (tubercullumhumeralislateralis) sampai dengan ujung tulang duduk (tubercullum ischiadium), diukur menggunakan tongkat ukur (satuan dalam $\mathrm{cm})$.

Lingkar dada (LD), diukur melingkar rongga dada dibelakang sendi tulang bahu (os scapula) menggunakan pita ukur (satuan dalam $\mathrm{cm}$ ).

b. Pada hasil penelitian ini berat badan sapi Bali di tentukan dengan menggunakan rumus Lambourne.

$$
B B=\frac{(L D)^{2} \times \text { PB }}{10840}
$$

\section{Analisa Statistik}

Analisis penampilan produksi Sapi Bali pada daerah dataran tinggi dan dataran rendah di Kabupaten Ngada dianalisis menggunakan uji T (Mendrofa, Priyanto, \& Komariah, 2016).

$$
\mathrm{T}_{\text {Hitung }}=\frac{\left|\overline{X_{A}}-\overline{X_{B}}\right|}{\sqrt{\frac{(n A)\left(S^{2} A\right)+(n B)\left(S^{2} B\right)}{n A+n B} \times\left(\frac{1}{n A}+\frac{1}{n B}\right)}}
$$

Keterangan: $X_{\mathrm{A}} \quad$ : Rata-rata sampel A, $X_{\mathrm{B}}$ : Rata-rata sampel B

$\mathrm{n}_{\mathrm{A}}$ : Jumlah data sampel A, $\mathrm{n}_{B}$ : Jumlah data sampel B

$\mathrm{S}_{\mathrm{A}}^{2} \quad$ : Ragam sampel A, $\mathrm{S}_{\mathrm{B}}^{2}$ : Ragam sampel B 


\section{Hasil dan Pembahasan}

\section{Bobot Lahir Sapi Bali}

Penelitian Digunakan Dalam Penelitian Ini Adalah Ternak Sapi Bali Sebanyak 246 Ekor (Data Produksi) Yang Ada Di 4 Kecamatan. Kecamatan Bajawa Dan Kecamatan Bajawa Utara Yang Mewakili Dataran Tinggi 131 Ekor Serta Kecamatan Riung Barat Dan Golewa Selatan Yang Mewakili Daratan Rendah 115 Ekor Yang Ada Di Kabupaten Ngada.

Tabel 2

Bobot Badan Pedet Sapi Bali

\begin{tabular}{lllll}
\hline Umur & Daerah & LD $(\mathbf{c m})$ & PB $(\mathbf{c m})$ & BB $(\mathbf{k g})$ \\
\hline 1 hari (Pedet) & DT $(\mathrm{n}=14)$ & $57,68 \pm 7,51$ & $50,74 \pm 4,99$ & $16,02 \pm 4,87$ \\
\hline & DR $(\mathrm{n}=16)$ & $54,34 \pm 3,79$ & $49,16 \pm 7,43$ & $13,58 \pm 3,41$ \\
\hline & Signifikansi & TBN & TBN & TBN \\
\hline
\end{tabular}

Dari tabel di atas menunjukan hasil penelitian ini lebih rendah bobot badan pedet sapi Bali dari penelitian (Eko Purwanto, 2012) dan lenih tinggi dari penelitian (Talib, Entwistle, Siregar, Budiarti-Turner, \& Lindsay, 2003) yang melaporkan bobot lahir sapi Bali di Nusa Tenggara Barat $(12,7+0,7 \mathrm{~kg})$, Bali $(16,08+1,6 \mathrm{~kg})$ dan Sulawesi Selatan (12,3+0,9 kg). Serta Panjaitan, Fordyce and Poppy (2003), yang menyatakan bobot lahir sapi Bali di Sumbawa sebesar 14,2+2,4 kg. Perbedaan tersebut menunjukkan bobot lahir dipengaruhi beberapa faktor diantaranya genetik (bangsa dan tetua) dan lingkungan (jenis kelamin pedet, lama kebuntingan, umur induk dan bobot induk serta pakan).

Dari data di atas menunjukan bahwa bobot badan pedet Sapi Bali di dataran tinggi berbeda nyata dengan bobot badan pedet sapi Bali di dataran rendah. Dan juga bobot badan pedet sapi Bali di dataran tinggi lebih berat di $(16,02 \pm 4,87)$ bandingkan dengan bobot badan pedet sapi Bali di datan rendah(13,58 $\pm 3,41)$. Hal ini menunjukan faktor musim dan lokasi pemeliharaan ikut berpengaruh terhadap bobot lahir anak, karena erat kaitannya dengan ketersediaan hijauan di lapangan. Pada musim hujan vegetasi yang tumbuh lebih beragam dan produksi hijauan lebih tinggi dibandingkan musim kemarau, sehingga anak yang dilahirkan pada musim hujan bobot lahirnya akan tinggi. Pada sapi Bali musim tidak berpengaruh terhadap bobot lahir. Menurut (Sasongko, Panjaitan, \& Muzani, 2005) melaporkan bahwa bobot lahir pedet jantan yang lahir pada musim kemarau sedikit lebih rendah produksinya dengan bobot anak yang lahir pada musim hujan yaitu $17,8 \pm 1,7 \mathrm{~kg}$ pada musim kemarau dan pada musim rata-rata bobot lahir pedet jantan lebih tinggi 17,9 $\pm 1,5 \mathrm{~kg}$ pada musim hujan. Bila dibandingkan dengan bobot lahir pedet betina rata-rata berada di bawah bobot lahir pedet jantan yaitu pada musim hujan 15,4+2,5 $\mathrm{kg}$ dan musim kemarau 16,0 $\pm 1,6 \mathrm{~kg}$. Pedet betina yang lahir pada musim kemarau lebih tinggi dibanding yang lahir pada musim hujan diduga karena faktor makanan yang lebih banyak diberikan legume pada musim kemarau sehingga nutrien yang 
terabsorpsi ke fetus lewat plasenta induknya belum mampu memberikan perbedaan pertumbuhan.

\section{Bobot Sapi}

Rataan dan simpangan baku bobot sapih sapi Bali hasil penelitian seperti disajikan pada Tabel 3 di bawah ini:

\begin{tabular}{lllll}
\multicolumn{4}{c}{ Tabel 3 } \\
\multicolumn{4}{c}{$\begin{array}{c}\text { Rataan Bobot Badan dan Ukuran Tubuh } \\
\text { Anak Sapi Bali Umur Sapih }\end{array}$} \\
\hline Umur & Daerah & LD $(\mathbf{c m})$ & PB $(\mathbf{c m})$ & BB $(\mathbf{k g})$ \\
\hline $0,5-1,5$ tahun $(\mathrm{P})$ & DT $(\mathrm{n}=44)$ & $97,58 \pm 11,76$ & $82,77 \pm 10,71$ & $73,77 \pm 20,28$ \\
\hline & DR $(\mathrm{n}=38)$ & $94,12 \pm 7,34$ & $84,15 \pm 9,48$ & $69,48 \pm 14,51$ \\
\hline
\end{tabular}

Dari tabel di atas menunjukan bahwa bobot badan sapih pada ternak sapi Bali di dataran tinggi lebih tinggi di bandingkan dengan dengan bobot badan ternak sapi Bali di dataran rendah, hal ini menunjukan perbedaan tempat atau lokasi dapat berpengaruh terhadap bobot sapih ternak sapi Bali (Sasongko et al., 2005). Bobot sapi banyak dipengaruhi faktor lingkungan diantaranya manajemen pemeliharaan dan produksi susu induk (Maylinda, 2010). Bobot sapih merupakan sifat yang dipengaruhi komponen genetik induk (maternal genetic effect) yaitu pengaruh gen yang mempengaruhi kondisi lingkungan pada induk yang mempengaruhi performa individu (Bourdon, 1997). Pengaruh maternal genetik antara lain adalah produksi susu dan tingkah laku menyusu induk sehingga bobot sapih juga dapat digunakan sebagai kriteria seleksi induk yang memiliki mothering ability baik.

Tabel di atas menunjukkan rataan bobot sapih di lokasi penelitian ini lebih rendah apabila dibandingkan dengan bobot sapih sapi Bali di P3 Bali yaitu $82,09+15,78 \mathrm{~kg}$ dan pulau Bali 91,77+7,25 kg (Supriyantono, 2006); di Nusa Tenggara Timur, Nusa Tenggara Barat, Bali dan Sulawesi Selatan masing-masing sebesar 79,2+18,2 kg, 83,9+25,9 kg, 82,9+8,2 kg dan 64,4+12,5 kg (Thalib, et al., 2002); sedangkan (Sasongko et al., 2005) memperoleh rataan bobot sapi Bali umur 6 bulan di Sumbawa sebesar $90+20 \mathrm{~kg}$.

Rataan ukuran tubuh sapi Bali pada umur sapih pada lokasi penelitian ini lebih tinggi dari yang dilaporkan (Handiwirawan, E., E. D. Setiawan, I. W. Mathius, Santoso, 1998) yang menyatakan lingkar dada dan panjang badan sapi Bali umur 60 - 90 hari sebesar 91,18+9,92 cm dan 71,73+8,11 cm. Pada tabel di atas menyatakan lingkar dada dan panjang badan sapi Bali umur 60 - 90 hari sebesar di lokasi penelitian menunjukan angka $97,58 \pm 11,76 \mathrm{~cm}$ dan $82,77 \pm 10,71 \mathrm{~cm}$ pada dataran tinggi sedangkan pada dataran rendah masing-masing $94,12 \pm 7,34 \mathrm{~cm}$ dan $84,15 \pm 9,48$ $\mathrm{cm}$. 


\section{Bobot Dewasa}

\section{Tabel 4}

Bobot Dewasa Sapi Bali Pada Lokasi Penelitian

\begin{tabular}{lllll}
\hline Umur & Daerah & LD $(\mathbf{c m})$ & PB $(\mathbf{c m})$ & BB $(\mathbf{k g})$ \\
\hline$>2-3$ tahun $(\mathrm{P})$ & DT $(\mathrm{n}=25)$ & $130,01 \pm 7,35$ & $107,79 \pm 11,40$ & $168,57 \pm 26,29$ \\
\hline & DR $(\mathrm{n}=15)$ & $122,21 \pm 5,33$ & $116,76 \pm 12,77$ & $160,97 \pm 21,01$ \\
\hline & Signifikansi & $* *$ & $*$ & TBN \\
\hline$>3-4$ tahun $(\mathrm{P})$ & DT $(\mathrm{n}=13)$ & $153,12 \pm 6,54$ & $133,46 \pm 7,95$ & $289,74 \pm 35,30$ \\
\hline & DR $(\mathrm{n}=11)$ & $144,40 \pm 4,62$ & $128,49 \pm 8,01$ & $247,25 \pm 20,57$ \\
\hline & Signifikansi & $* *$ & TBN & $* *$ \\
\hline$>4$ tahun $(\mathrm{P})$ & DT $(\mathrm{n}=22)$ & $174,05 \pm 10,68$ & $143,08 \pm 15,18$ & $404,90 \pm 89,20$ \\
\hline & DR $(\mathrm{n}=23)$ & $166,13 \pm 11,39$ & $141,43 \pm 17,11$ & $366,14 \pm 95,20$ \\
\hline
\end{tabular}

Tabel di atas menunjukkan umur sapi Bali pada umur >2-3 lingkar dada berbeda sangat nyata antara dataran tinggi dan lingkar dada pada dataran rendah. Sedangkan pada panjang badan berbeda nyata antara dataran tinggi dan dataran rendah. Pada umur >3-4 tahun lingkar dada dan bobot badan menunjukan berbeda sangat nyata antara dataran tinggi dan dataran rendah. Pada umur $>4$ tahun lingkar dada menunjukan berbeda nyata antara dataran tinggi dan dataran rendah. Dan pada keseluruhan bobot badan ternak sapi Bali menunjukan bobot badan ternak sapi Bali di dataran tinggi lebih rendah di bandingkan dengan bobot badan pada dataran rendah.

Perbedaan bobot badan hasil penelitian ini dengan penelitian terdahulu diduga disebabkan karena faktor lingkungan. Faktor lingkungan tidak seluruhnya dapat diseragamkan karena pola pemeliharaan ternak tiap tahun tidak sama sehingga secara tidak langsung akan mempengaruhi tampilan bobot hidup. Pakan walaupun hampir sama dan selalu tersedia dalam jumlah yang cukup tetapi pada kondisi peternakan yang ada di kabupaten Ngada. Pengaruh faktor lingkungan terhadap individu satu dengan individu lainyang tidak sama akan menimbulkan variansi lingkungan. Pengaruh variansi genetik suatu sifat pada suatu populasi ternak hanya dapat diketahui apabila variansi lingkungan yang mempengaruhi sifat tersebut dapat ditiadakan.

Dari beberapa hasil penelitian menunjukkan bahwa sapi Bali memberikan respon positif terhadap perbaikan pakan dengan meningkatnya laju pertambahan bobot badan.Rataan laju pertambahan bobot badan (PBB) sapi Bali yang diberi rumput lapangan tanpa diberipakan tambahan adalah 175,75 g/ekor/hari,namun PBB harian meningkat jika diberi pakantambahan konsentrat 1,8\% hingga mencapai313,88 g/ekor/hari (Amril, Rasjid, \& Hasan, 1990). (Soemarmi \& Wardhani, 1985) melaporkan laju PBB sapi Bali mencapai 690 dan 820 g/ekor/hari berturut-turut yang diberi pakan rumput dan pucuk tebu ditambah konsentrat $1 \%$. Pada penelitian ini para peternak tidak memberikan perlakuan khusus pada pemberian pakan, pakan diberikan dalam bentuk segar tanpa perlakuan pengembangan teknologi yang ada. 


\section{Pertambahan Bobot Badan}

Hasil rataan dan simpangan bakupertambahan bobot badan sapi Bali di lokasi penelitian yang disajikan pada Tabel 5.

Tabel 5

Rataan Pertambahan Bobot Badan Sapi Bali

\begin{tabular}{cc}
\hline Daerah & PBBH \\
\hline DT $(\mathrm{n}=7)$ & $0,61 \pm 0,02$ \\
DR $(\mathrm{n}=8)$ & $0,53 \pm 0,19$ \\
Signifikansi & TBN \\
\hline
\end{tabular}

Tabel 5 menunjukkan bahwa rataan pertambahan berat badan sapi Bali dewasa di lokasi penelitian lebih tinggi dari yang dilaporkan (Salim, Susilawati, \& Wahyuningsih, 2012), rataan PBB sapi Bali Pandaan adalah 0,41+0,18 kg $\mathrm{kg} / \mathrm{ekor} /$ hari tetapi hampir sama dengan penelitian (Pane, 1991) yang melaporkan pertambahan bobot badan sapi Bali dengan pakan yang baik dapat mencapai 0,7 $\mathrm{kg} /$ hari (jantan dewasa) dan 0,6 kg/hari (betina dewasa). (Bahar, 2003) melaporkan bahwa pertambahan bobot badan harian $(\mathrm{PBBH})$ sapi bali yangdigembalakan dengan pakan hijauan lokal pada musimkemarau berkisar antara 0,05-0,1 kg/ekor/hari, sedangkan pada musim hujan antara 0,2-0,4 kg/ekor/hari. Perbedaan pertambahan bobot badan ini disebabkan karena perbedaan jumlah dan mutu pakan, jenis kelamin, umur induk, tahun kelahiran, musim dan pertumbuhan ternak (genetik). Pada lokasi penelitian yaitu di Kabupaten Ngada memiliki ketersediaan pakan yang banyak dan memadai ini di karenakan setiap peternak memiliki kebun Hijaun Pakan (HMT) Sendiri. Dan jumlah ternak yang di pelihara juga berfariasi antara 2-3 ekor per Kepala Keluarga. Hal ini juga berpengaruh karena peternak lebih fokus memelihara karena jumlah ternak yang di pelihara terbatas dan jumlah HMT yang memadai.

\section{Kesimpulan}

Berdasarkan hasil penelitian dapat disimpulkan bahwa: 1) Produktivitas sapi Bali yang ada di Kabupaten Ngada, Flores, Nusa Tenggara Timur di pengaruhi oleh beberapa ketinggian tempat 2) Populasi sapi Bali di Kabupaten Ngada Mengalami peningkatan dari tahun ke tahun. 


\section{BIBLIOGRAFI}

Amril, M. A., Rasjid, S., \& Hasan, S. (1990). Rumput lapangan dan jerami padi amoniasi urea sebagai sumber hijauan dalam penggemukan sapi Bali jantan dengan makanan penguat. Pros. Seminar Nasional Sapi Bali, 20-22. Google Scholar

Arikunto, Suharsimi. (2010). Prosedur Penelitian Pendidikan Suatu Pendekatan Praktik. Jakarta: Rineka Cipta. Google Scholar

Bahar, S. dan Rakhmat. (2003). Kajian pertumbuhan sapi bali yang digembalakan dengan pakan hijauan lokal. Prosiding Seminar Nasional Teknologi Peternakan Dan Veteriner. Bogor.

Bourdon, R. M. (1997). Heritability and repeatability. Understanding Animal Breeding, 149-184. Google Scholar

Calderon, A., D.V. Armstrong, D.E. Ray, S.K. Denise, R. M. Enns and C. M. Howison. (2005). Productive and Reproductive Response of Holstein and Brown Swiss Heat Stressed Dairy Cows to Two Different Cooling Systems.

Epaphras, A., Karimuribo, E. D., \& Msellem, S. N. (2004). Effect of season and parity on lactation of crossbred Ayrshire cows reared under coastal tropical climate in Tanzania. Livestock Research for Rural Development, 16(6), 42-46. Google Scholar

Handiwirawan, E., E. D. Setiawan, I. W. Mathius, Santoso, dan A. Sudibyo. (1998). No Title. Ukuran Tubuh Anak Sapi Bali Dan Persilangannya Di Nusa Tenggara Barat. Prosiding Seminar Nasional Peternakan Dan Veteriner. Google Scholar

Karnaen, Karnaen, \& Arifin, J. (2009). Correlation of Breeding Values Among Test Day Record at First, Second, and Third Lactations on Milk Production of Dairy Cattle. Animal Production, 11(2). Google Scholar

Mendrofa, V. A., Priyanto, R., \& Komariah, Komariah. (2016). Sifat Fisik dan Mikroanatomi Daging Kerbau dan Sapi pada Umur yang Berbeda. Jurnal Ilmu Produksi Dan Teknologi Hasil Peternakan, 4(2), 325-331. Google Scholar

Pane, Ismed. (1991). Produktivitas dan breeding sapi Bali. Proc. Seminar Nasional Sapi Bali, 2-3. Google Scholar

Salim, Muhammad Ade, Susilawati, Trinil, \& Wahyuningsih, Sri. (2012). Pengaruh metode thawing terhadap kualitas semen beku sapi Bali, sapi Madura dan sapi PO. Jurnal Agripet, 12(2), 14-19. Google Scholar

Sasongko, W. R., Panjaitan, Tanda, \& Muzani, Achmad. (2005). Kementerian Pertanian. Google Scholar

Soemarmi, A. Musofie, \& Wardhani, N. K. (1985). Effect of sugar cane top on daily 
Performa Produksi Sapi Bali pada Ketinggian Tempat yang Berbeda di Kabupaten Ngada, Flores, Nusa Tenggara Timur

weight gain of male Bali cattle. Proc. Seminar the Use of Sugarcane Waste for Animal Feed. Grati. Center Research in Animal Science. Google Scholar

Supriyantono, A. (2006). Estimasi parameter geneti inerja produ si dan reprodu si sebagai dasar penyusunan program pemuliaan pada sapi Bali: Studi Kasus di P3 Bali [Disertasi].[Malang (Indonesia)]: Universitas Brawijaya. Google Scholar

Talib, C., Entwistle, K., Siregar, A., Budiarti-Turner, S., \& Lindsay, D. (2003). Survey of population and production dynamics of Bali cattle and existing breeding programs in Indonesia. ACIAR Proceedings, 3-9. ACIAR; 1998. Google Scholar

Umiyasih, U., Yusran, Aryogi M. A., Wijono, D. B., \& Wahyono, D. E. (2000). Pengkajian teknologi penggemukan sapi potong. PROSIDING, 555. Google Scholar

\section{Copyright holder:}

Ngiso Bhae, Suyadi, M. Nur Ihsan (2022)

First publication right:

Syntax Literate: Jurnal Ilmiah Indonesia

This article is licensed under: 